\title{
Spatial relationship between the atmospheric circulation and the precipitation measured in the western Swiss Alps by means of the analogue method
}

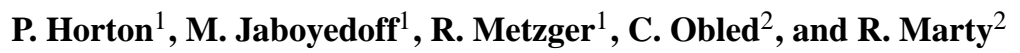 \\ ${ }^{1}$ Institute of Geomatics and Analysis of Risk (IGAR), University of Lausanne, Switzerland \\ ${ }^{2}$ Grenoble-INP, LTHE UMR5564, Grenoble, France \\ Correspondence to: P. Horton (pascal.horton@unil.ch)
}

Received: 21 April 2011 - Revised: 6 February 2012 - Accepted: 28 February 2012 - Published: 23 March 2012

\begin{abstract}
An adaptation technique based on the synoptic atmospheric circulation to forecast local precipitation, namely the analogue method, has been implemented for the western Swiss Alps. During the calibration procedure, relevance maps were established for the geopotential height data. These maps highlight the locations were the synoptic circulation was found of interest for the precipitation forecasting at two rain gauge stations (Binn and Les Marécottes) that are located both in the alpine Rhône catchment, at a distance of about $100 \mathrm{~km}$ from each other. These two stations are sensitive to different atmospheric circulations.
\end{abstract}

We have observed that the most relevant data for the analogue method can be found where specific atmospheric circulation patterns appear concomitantly with heavy precipitation events. Those skilled regions are coherent with the atmospheric flows illustrated, for example, by means of the back trajectories of air masses. Indeed, the circulation recurrently diverges from the climatology during days with strong precipitation on the southern part of the alpine Rhône catchment. We have found that for over 152 days with precipitation amount above $50 \mathrm{~mm}$ at the Binn station, only 3 did not show a trajectory of a southerly flow, meaning that such a circulation was present for $98 \%$ of the events.

Time evolution of the relevance maps confirms that the atmospheric circulation variables have significantly better forecasting skills close to the precipitation period, and that it seems pointless for the analogue method to consider circulation information days before a precipitation event as a primary predictor. Even though the occurrence of some critical circulation patterns leading to heavy precipitation events can be detected by precursors at remote locations and 1 week ahead (Grazzini, 2007; Martius et al., 2008), time extrapolation by the analogue method seems to be rather poor. This would suggest, in accordance with previous studies (Obled et al., 2002; Bontron and Obled, 2005), that time extrapolation should be done by the Global Circulation Model, which can process atmospheric variables that can be used by the adaptation method.

\section{Introduction}

Some major precipitation events recently occurred in the Swiss alpine Rhône catchment (1987, 1993 and 2000). October 2000 is the last to date with precipitation amounts above $500 \mathrm{~mm}$ in 7 days in the south-eastern part of the catchment (Petrascheck and Hegg, 2002). According to present statistics, this event has a return period of more than 1000 years for different rain gauges. This created a 100 to 300-yr flood on the Rhône, depending on the location (Petrascheck and Hegg, 2002).

This work is part of the MINERVE (Modélisation des Intempéries de Nature Extrême sur les Rivières Valaisannes et de leurs Effets) project that aims at providing a realtime flood management on the upper Rhône catchment (García Hernández et al., 2009). The main idea is to use dams to store water during an extreme event. This means that a certain storage volume must be made available before the precipitation begins. This requires the precipitation and the discharge to be predicted several days in advance. At present, MeteoSwiss provides the COSMO (Consortium for Small-scale Modeling, see Steppeler et al., 2003) and COSMO-LEPS (Limited Area Ensemble Prediction System, see Montani et al., 2003; Marsigli et al., 2005) forecasts. Our work aims at providing a parallel forecast based on a statistical approach, namely the analogue method, in order to 


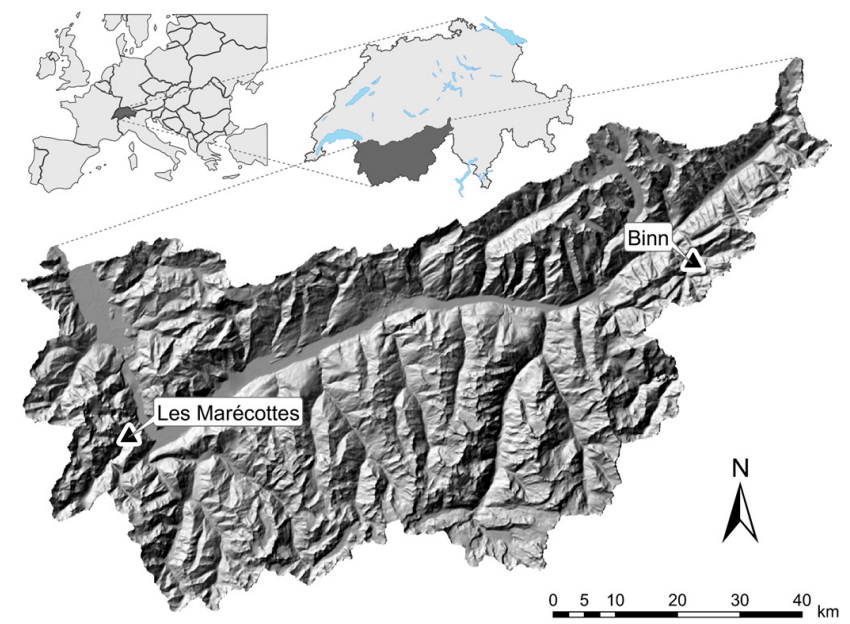

Fig. 1. Location of the alpine Rhône catchment in Switzerland and the two rain gauge stations of interest (source: Swisstopo).

better assess the meteorological uncertainties. It will also give an overview of the synoptic atmospheric circulation and its identified determining elements, and offer the possibility to refer to historical events.

The analogue method is an adaptation technique that allows forecasting daily (and possible subdaily) precipitation by means of identification of analogue past situations in terms of synoptic circulation. The chosen method is similar to the one developed by Obled et al. (2002), Bontron and Obled (2005), Ben Daoud et al. (2009) and Marty et al. (2012). This study covers part of the method calibration for the Swiss Alps. The parameters' space is highly multidimensional, which means that the calibration process cannot be easily automatised. The purpose of this study is to perform diagnostic analyses that could help the calibration and provide guidelines for the selection of predictor variables.

Strong southerly flows, which are critical for precipitation on the eastern part of the Rhône catchment, have been the subject of many studies. These show the presence of upperlevel precursors in potential vorticity fields and in geopotential heights (e.g. Massacand et al., 1998; Martius et al., 2006, 2008; Grazzini, 2007, etc.). We will show similar analyses by means of backward trajectories of air masses, and set these in perspective with the regions of the geopotential levels having the highest skill for precipitation forecasting at gauging stations of interest.

\section{Data and methodology}

The study area is the alpine upper Rhône catchment in Switzerland (Fig. 1). The altitude ranges from 372 to $4634 \mathrm{~m}$ a.s.l. and the area is $5524 \mathrm{~km}^{2}$.

Our calibration is illustrated in 2 locations (Fig. 1) that are sensitive to different atmospheric circulations. Les Marécottes is sensitive to strong westerlies, while Binn is extremely sensitive to the southerly circulation. This last one was actually the circulation pattern of October 2000 and it is the most critical situation for the catchment. It can generate large amounts of precipitation on the eastern or southern part of the catchment by strong orographic effects.

\subsection{Datasets and tools}

The chosen dataset is the NCEP/NCAR reanalysis (6-hourly, 17 atmospheric levels at a resolution of $2.5^{\circ}$; see Kalnay et al., 1996), as predictor variables and the daily precipitation measured at the MeteoSwiss stations network as predictand (which is to be predicted), for the period 1962-2007. Other authors usually consider a precipitation averaged over a basin or a region as the predictand in order to smooth local effects (Obled et al., 2002; Marty et al., 2012), which is not the case in the present study.

We developed the model used for this study, which is called ATMOSWING (Analogue Technique MOdel for Statistical Weather forecastING), and is written in $\mathrm{C}++$ with an object-oriented architecture. It allows us to process calibration and real-time forecasting and to visualize the outputs. This model has been intensively tested against the model developed at the Grenoble Institute of Technology (Bontron and Obled, 2005; Marty et al., 2012) to ensure that the processing is correct.

\subsection{The analogue adaptation technique}

The analogue method is a downscaling technique based on the idea expressed by Lorenz (1969). It aims at forecasting a predictand, often the daily precipitation, on the basis of predictor variables describing the synoptic atmospheric circulation. Its main hypothesis is that similar situations in terms of atmospheric circulation are likely to lead to similar local weather (Bontron and Obled, 2005). This has been observed for the Alpine region in various studies (Massacand et al., 1998; Grazzini, 2007; Martius et al., 2006, 2008; Fehlmann et al., 2000).

The approach consists of the following steps. The method summarized hereafter is similar to the approach of Obled et al. (2002), Bontron and Obled (2005), Ben Daoud et al. (2009) and Marty et al. (2012). Numerous variations of the method are possible, and some aspects and parameters will not be detailed hereafter. In the following procedure, we are interested in forecasting the cumulated daily rainfall (6 a.m. to 6 a.m. the next day) for the 7 coming days, $D_{1}$ to $D_{7}$.

1. We collect some predictors (geopotential heights and humidity variables) for our 7 lead times ( $D_{1}$ to $D_{7}$ ) from the Global Circulation Model (GCM) outputs in the case of real-time forecasting or from the reanalysis dataset (Kalnay et al., 1996) in the case of the calibration procedure. The predictor data are thus already extrapolated over time. 
2. Then, we process the first level of analogy on the synoptic circulation. Bontron and Obled (2005) showed that the geopotential heights at $500 \mathrm{hPa}$ and $1000 \mathrm{hPa}$ are the best first predictors of the NCEP/NCAR reanalysis dataset. Thus, these fields are extracted over a certain spatial window for every target date $D_{j}$ to be compared to the reanalysis archive. To cope with seasonal effects, candidate data are extracted for every year from the archive within a period of 4 months centred around the target date $D_{j}$. The similarity criterion is the S1 score given in Eq. (1), which is a comparison of gradients (Teweles and Wobus, 1954; Drosdowsky and Zhang, 2003).

$$
\mathrm{S} 1=100 \frac{\sum_{i}\left|\Delta \hat{z}_{i}-\Delta z_{i}\right|}{\sum_{i} \max \left\{\left|\Delta \hat{z}_{i}\right|,\left|\Delta z_{i}\right|\right\}}
$$

where $\Delta \hat{z}_{i}$ is the forecast geopotential height difference between the $i$-th pair of adjacent points in the target situation, and $\Delta z_{i}$ is the corresponding observed geopotential height difference in the candidate situation. The differences are processed separately in both directions, and then averaged. The smaller the S1 values are, the more similar the pressure fields.

The S1 score has been compared against other criteria by Bontron and Obled (2005). The RMSE is better to compare most variables, except the geopotential heights. In this case, S1 shows improved forecasting skills. The reason for such better results is that the S1 criteria allows comparing the circulation pattern, by means of the gradients, rather than the absolute value of the geopotential heights.

3. The $N_{j}$ dates with the lowest values of $\mathrm{S} 1$ are considered as analogues to the target day $D_{j}$. The number of analogues, $N_{j}$, is a parameter to calibrate that varies with the lead time $j$ in the forecast usage. It has an optimum clearly identifiable that is often around 30 dates for the first lead time $(j=1)$ if we consider only one level of analogy, and that is increasing for subsequent lead times.

4. We may next add new subsampling levels based on other variables, such as the humidity fluxes, to pick out a lower number of analogues $N_{j}^{\prime}$ amongst the previous selection. If we consider a second level of analogy, the first number of analogues, $N_{j}$, needs to be higher than in the case of a single level approach. Naturally, $N_{j}^{\prime}<N_{j}$.

5. Finally, the daily observed precipitation amount of the $N_{j}^{\prime}$ resulting dates provides the empirical conditional distribution, considered as the probabilistic forecast for the target day $D_{j}$.

\subsection{Calibration}

For every level of analogy, a parameter one has to calibrate is the analogues number. In each of these levels, for every atmospheric variable, we also need to calibrate:

- The best atmospheric levels to select

- The spatial windows (their location and size)

- The temporal windows (hour of the day)

To calibrate the method, we need to reforecast the past and to assess the performance of our model by comparing the results to observed precipitation. As the GCM outputs are not available in a forecasting mode for the past, the calibration is performed in a perfect prognosis framework with the reanalysis dataset. This means that the predictors are analysed fields and not output forecasts from a meteorological model, and thus have a smaller and constant uncertainty when model forecasts show an increasing uncertainty with the lead time.

The calibration is done by means of a trial and error approach: we choose an initial parameters set, run the model over a long calibration period (1962-2007) and assess the result. The model accuracy is rated by means of the CRPS (Continuous Ranked Probability Score) (Brown, 1974; Matheson and Winkler, 1976; Hersbach, 2000). Let the precipitation variable be denoted $x$ with $x^{0}$ the observed value, and $F(x)$ the predicted cumulative distribution functions (cdf). The mean CRPS of a forecast series of length $n$ can be written as:

$\mathrm{CRPS}=\frac{1}{n} \sum_{i=1}^{n}\left(\int_{-\infty}^{+\infty}\left[F_{i}(x)-H_{i}\left(x-x_{i}^{0}\right)\right]^{2} d x\right)$

where $H\left(x-x_{i}^{0}\right)$ is the Heaviside function that is null when $x-x_{i}^{0}<0$, and is equal to 1 otherwise.

The mean CRPS is processed on the calibration period. The best parameters are selected according to the optimal (i.e. lowest) score.

\subsection{Relevance mapping}

The relevance map is a spatial representation of the forecasting skill of every grid cell of the predictor dataset. This map is processed by fixing every parameter except the location of a unitary sized spatial window that moves across the whole map (Bontron and Obled, 2005). By iterating the position of this small window, we get the CRPS score corresponding to every spatial unit. It allows us to see where the synoptic circulation information is relevant to explain the precipitation time series at our rain gauge station. The relevance mapping was processed on the whole time series (including days without precipitation).

The predictors' best locations are not expected to be the same for different stations or sub-catchments, but to match 

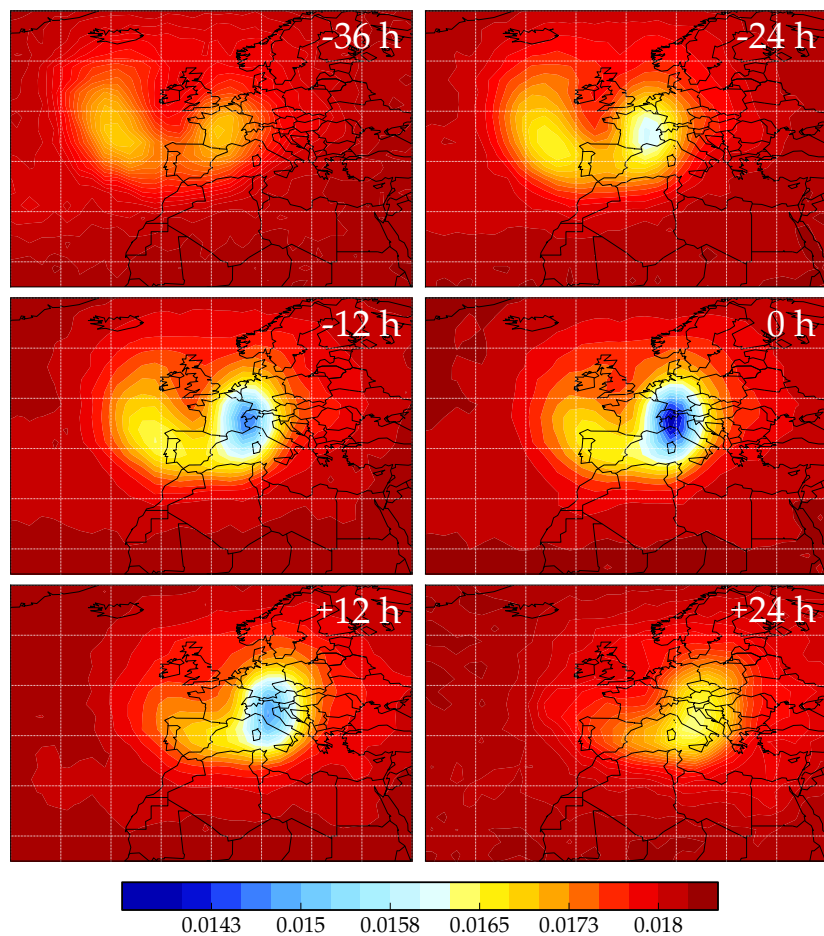

Fig. 2. Time evolution of the relevance map on the $500 \mathrm{hPa}$ atmospheric pressure level for the Binn station. The values are the CRPS scores.

the meteorological characteristics of the region. The predictors' best locations should indeed be consistent with the meteorological phenomena that influence the region's weather.

\subsection{Isobaric back trajectories}

We processed isobaric back trajectories (Danielsen, 1961) of air masses on the wind field of the NCEP/NCAR reanalysis dataset (Kalnay et al., 1996) for days above a certain amount of precipitation at the station of interest. The starting location is the central point of the Rhône catchment. As the resolution of the dataset is rather coarse compared to the catchment size, the hypothesis is made that there is no significant variation of the synoptic circulation information for distances of about $50 \mathrm{~km}$, which are subgrid scales.

\section{Results for the Rhône catchment}

\subsection{Relevance maps evolution}

As the NCEP/NCAR reanalysis has higher time resolution than the rainfall series, we had to choose the best temporal window to compare the predictor variables. To illustrate the effect of the hour selection, as well as the time extrapolation influence for the method, some relevance maps (Sect. 2.4) were established for various hours around the precipitation period. This was made by considering the predictor at a time $h+\Delta t$ to predict the precipitation at time $h$ with $\Delta t$ varying
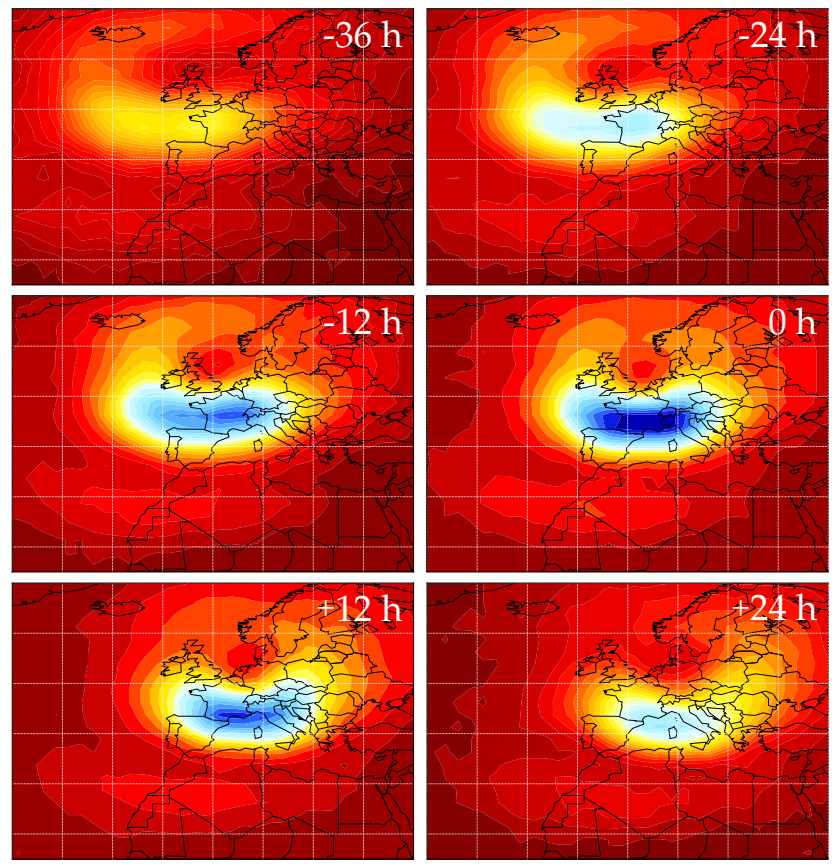

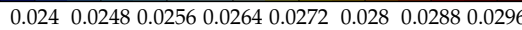

Fig. 3. Time evolution of the relevance map on the $500 \mathrm{hPa}$ atmospheric pressure level for the Marécottes station. The values are the CRPS scores.

in between $-36 \mathrm{~h}$ and $+24 \mathrm{~h}$. Precipitation time $h$ is 6 p.m., being the center of the measuring period ( 6 a.m. to 6 a.m. the next day).

The evolution on the $500 \mathrm{hPa}$ level for the Binn (Fig. 2) and Marécottes stations (Fig. 3) illustrates the formation of the patterns where the atmospheric circulation is determining the whole precipitation time series. One can see the patterns being formed at some remote distance some hours before the precipitation period. These patterns evolve and move over the catchment, where they reach their strongest relevance, before continuing to travel eastward and losing their predictability skill. These patterns characterize the relevant regions in terms of atmospheric circulation, by means of the geopotential field gradients.

\subsection{Relevance maps optimums}

The relevance maps were processed for both the Binn and Marécottes stations at $500 \mathrm{hPa}$ and $1000 \mathrm{hPa}$, each with its optimal temporal window (Fig. 4). The hour is expressed relatively to the center (6:00 p.m.) of the precipitation measuring period (6:00 a.m.-6:00 a.m. the next day), resulting in a time difference $\Delta t$. One can see that if the time matches the precipitation period for both stations on the $500 \mathrm{hPa}$, it varies from $-6 \mathrm{~h}$ at Binn to $+6 \mathrm{~h}$ at Les Marécottes on the $1000 \mathrm{hPa}$. 

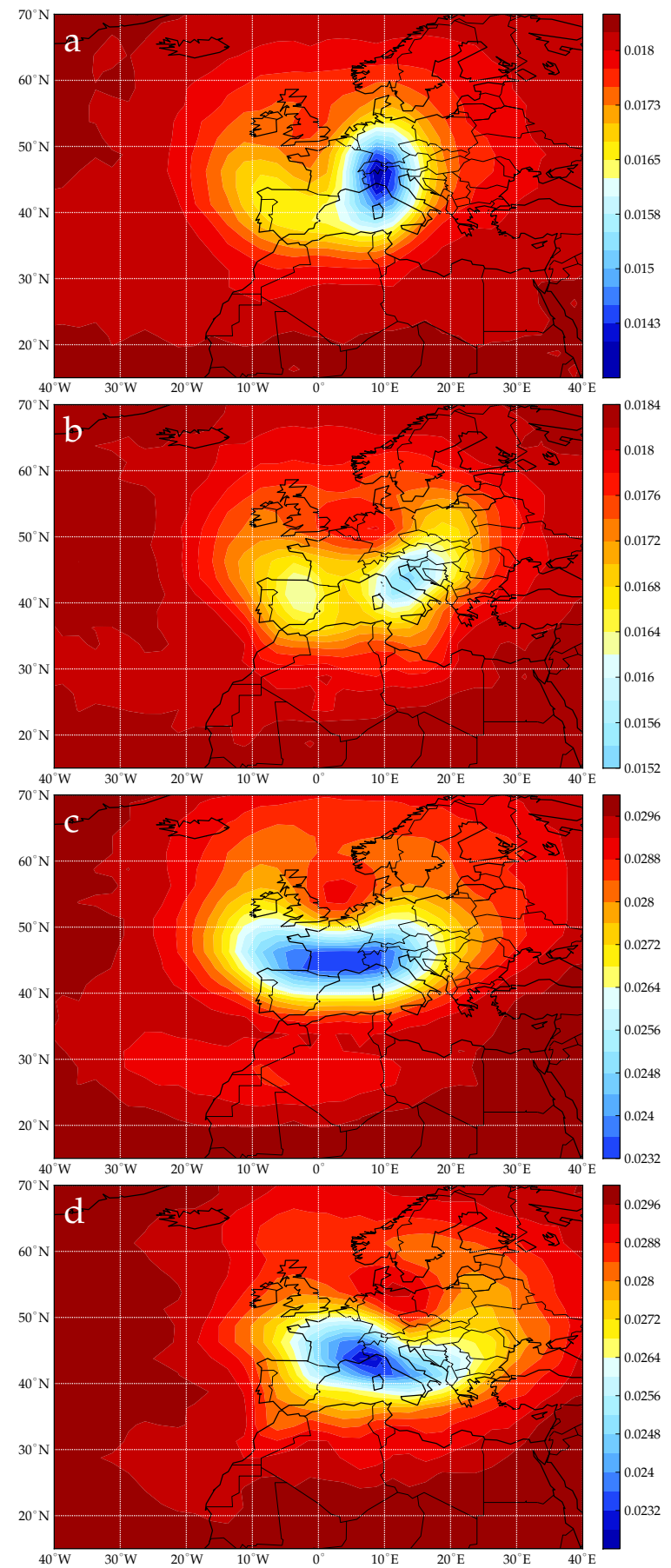

Fig. 4. Relevance map (a) on the $500 \mathrm{hPa}$ at $\Delta t=0 \mathrm{~h}$ and (b) on the $1000 \mathrm{hPa}$ at $\Delta t=-6 \mathrm{~h}$ for the Binn station, and (c) on the $500 \mathrm{hPa}$ at $\Delta t=0 \mathrm{~h}$ and (d) on the $1000 \mathrm{hPa}$ at $\Delta t=+6 \mathrm{~h}$ for the Marécottes station. The values are the CRPS scores.

The CRPS score cannot be compared between the stations, but it can be compared between atmospheric levels for one station. The reduced range of values for any map is due to the fact that we consider spatial windows with size of a grid cell to search for analogues, which is clearly not the optimal

extent. Adaptation of the spatial window size, which is the next step following the relevance map in the calibration process, greatly increases the forecasting skills of the method.

As one can see on the two relevance maps for Binn (Fig. 4a and $4 \mathrm{~b}$ ), the $500 \mathrm{hPa}$ level explains the precipitation in that region better than the $1000 \mathrm{hPa}$. The difference is significant and may be explained by the heterogeneity on the $1000 \mathrm{hPa}$ level. Indeed, this level shows a first optimal location in the Adriatic Sea and over Italy and a second minor over Spain. Another potential reason for the importance of the $500 \mathrm{hPa}$ level is the need of a strong upper-level current for the precipitation to reach the other side of the orographic barrier with a remarkable intensity (Massacand et al., 1998).

On the opposite, the relevance maps for the Marécottes station (Fig. 4c and d) show a better score for the $1000 \mathrm{hPa}$ level than for the $500 \mathrm{hPa}$.

For both stations, the most relevant areas include the catchment on the $500 \mathrm{hPa}$ level, but not on the $1000 \mathrm{hPa}$ on which they are located further south. By the way, it makes us more confident to consider the $1000 \mathrm{hPa}$ level above the sea rather than in the Alps, where its significance it debatable.

\section{Meteorological analyses}

We will first discuss the meteorological situations leading to heavy precipitation events at the Binn station. It is well known that southerly circulations are critical for this location, particularly in autumn. Such a flow may trigger high precipitation events on the Alpine southern slopes by orographic lifting (Massacand et al., 1998). Sometimes, but not always, high precipitation amounts may reach the Rhône catchment. When this happens, the Binn region is concerned most of the time.

Analyses of some events of extreme precipitation on the Alpine south side indicate the presence of an upper-level precursor on the potential vorticity distribution (Massacand et al., 1998). These events could be characterized by similar potential vorticity patterns taking the form of a meridionally elongated deep intrusion of stratospheric air. Martius et al. (2006) found a strong correlation between this potential vorticity streamer and extreme precipitation on the southern slopes of the Alps (streamers are present for $73 \%$ of extreme precipitation days). The upper-level circulation was accordingly characterized by a deep trough at $500 \mathrm{hPa}$ extending from the British Isles towards the Iberian Peninsula at the time of the precipitation (Fehlmann et al., 2000; Plaut et al., 2001). This trough was accompanied by an upper-level ridge to the west ensuring air advection, and another one to the east, which contributed to blocking the perturbation (Fehlmann et al., 2000; Plaut et al., 2001). The consequences of such a system are a moisture-laden strong southerly flow at low levels that extends from the Mediterranean to the Alps, a reduction of the static stability, and an enhancement of the convection (Massacand et al., 1998). 


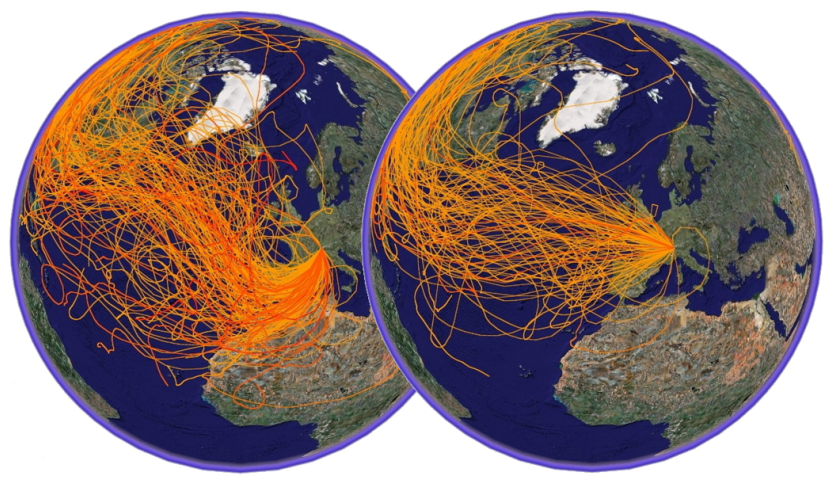

Fig. 5. Isobaric back trajectories at $500 \mathrm{hPa}$ of the days with precipitation above $50 \mathrm{~mm}$ (left) at the Binn and (right) the Marécottes station (source: GoogleEarth).

Grazzini (2007) states that "since the incident airflow is mostly controlled by the large-scale pressure gradient we assume that strong southerly flow conditions can be broadly described in terms of the $500 \mathrm{hPa}$ height field". He calculated a reference pattern and its associated anomaly for the most intense events on Alpine southern slopes and the Rhône catchment by averaging the $500 \mathrm{hPa}$ height fields. It revealed the elongated meridional trough and a sharp pressure gradient on its east side.

These troughs may result from amplification of Rossby waves (Grazzini, 2007; Martius et al., 2008), and thus are generated by an evolving system that finds its origin at remote locations. The wave-packet at high levels is propagating from the Pacific region for autumn and winter cases, and can be traced back to approximately 1 week ahead (Grazzini, 2007; Martius et al., 2008). The onset of strong southerly flow is more predictable than its decay (Grazzini, 2007). This may be due to satisfactory modelling of the strong dynamical forcing associated with Rossby-wave propagation (Grazzini, 2007), while the dissipation stage characterized by wavebreaking phenomena and local processes does imply the less robust physical part of the model.

Plaut et al. (2001) worked on clustering large-scale circulation patterns of many heavy precipitation days $\left(\geq 50 \mathrm{~mm} \mathrm{~d}^{-1}\right.$ ) for different sub-regions. Two of the three clusters he obtained for Ticino and the eastern part of the Rhône catchment are coherent with the circulation we observed. These are composed of anomalies on the $700 \mathrm{hPa}$ level that reveal the location of the troughs, around which air masses flow. However, we won't go into details, as Martius et al. (2006) showed that Ticino and the eastern Rhône catchment present some differences in the location and the orientation of their associated streamers. High precipitation days coincide only in about $50 \%$ of the cases for the eastern Rhône catchment, Ticino and Grisons, and are exclusively in one of the three regions otherwise.

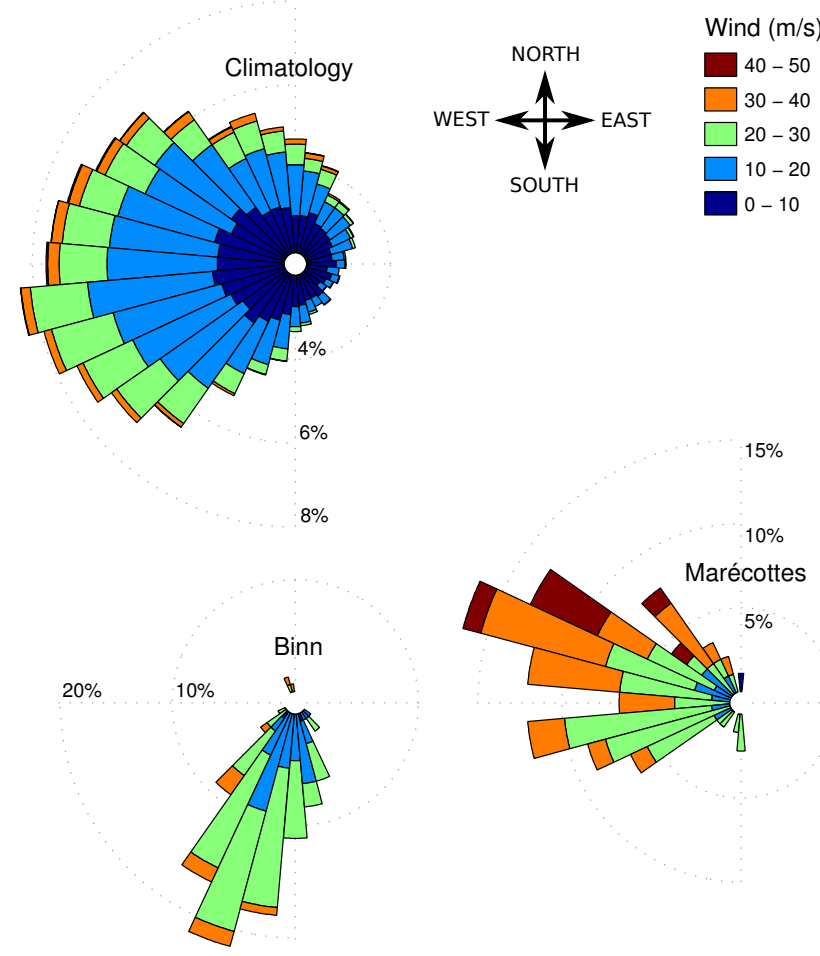

Fig. 6. Wind roses made with the NCEP/NCAR reanalysis dataset at the central point of the catchment on the $500 \mathrm{hPa}$ level; wind roses of the climatology and of the days with precipitation above $50 \mathrm{~mm}$ at the Binn and Marécottes stations.

A strong southerly flow seems to be necessary for extreme precipitation events on Alpine southern slopes, but other factors also need to be taken into account, as the occurrence of this flow is greater than that of extreme precipitation (Martius et al., 2006; Grazzini, 2007). Streamers are frequent over Western Europe and heavy precipitation is not always observed (Martius et al., 2006).

The back trajectories of air masses (Sect. 2.5) at $500 \mathrm{hPa}$ for the days with more than $50 \mathrm{~mm}$ of precipitation at the Binn station (Fig. 5 left) show a clear tendency that diverges from the climatology characterized by the zonal flow (Horton et al., 2009). Their atmospheric circulation has a strong southerly component close to the station, which is consistent with the presence of the trough previously described. While such circulations were observed only for a part of large sample of events in previous studies, it appears here to be almost a constant rule for daily precipitation amounts $\geq 50 \mathrm{~mm}$ at the Binn station. We found indeed that of over 152 days with precipitation above $50 \mathrm{~mm}$ at the Binn station, only 3 (in late November and December) did not show a trajectory with a southerly flow, meaning that such a circulation was present for $98 \%$ of the events.

Another illustration of this same information is the wind rose for Binn (Fig. 6 left). The wind roses were also established on the NCEP/NCAR reanalysis dataset at the central 
point of the catchment. We can see that the days with strong precipitation at the Binn station have an important southerly flow at $500 \mathrm{hPa}$ that diverges from the average climatology. It is information that exists in the reanalysis dataset and that can be useful in a downscaling approach.

Doing the same for the Marécottes station, we can see on the back trajectories (Fig. 5 right) and the wind rose (Fig. 6) that the west component is dominating. This corresponds to the westerlies, and thus makes the direction information relatively useless to discriminate the critical situations. However, the wind intensity is much more important than the average climatology, and thus represents a discrimination potential in a downscaling model.

When we compare the back trajectories for severe rainfall events and the relevance maps at $500 \mathrm{hPa}$, processed on the whole series, the similarities are obvious. For Binn, the relevance map shows the curvy circulation patterns characterizing the southerly flow that produces heavy precipitation at the station. The same analysis can be made on the Marécottes station, with a prevailing west circulation during heavy precipitation events.

These analyses confirm that the most relevant data for the analogue method can be found where specific atmospheric circulation patterns appear concomitantly with heavy precipitation events.

\section{Conclusions}

The analysis of the back trajectories and the wind roses reveals first that the reanalysis dataset contains valuable information for a statistical downscaling method despite of its resolution $\left(2.5^{\circ}\right)$. It also reveals that the atmospheric circulation diverges from the average climatology during heavy precipitation events and that a strong recurrence of the conditions is visible for those days. We have found that of over 152 days with heavy precipitation at the Binn station, only 3 do not show a trajectory of a southerly flow. This reveals a strong precursor that can be used in an adaptation method such as the analogue method.

Events in the Binn region require a special configuration of the circulation at the global scale to produce heavy precipitation for several days (Buzzi et al., 1998). Complex local phenomena such as topographic enhancement, convection or moisture fluxes have an influence over the precipitation amount, but large-scale flow is equally important in producing the necessary conditions (Grazzini, 2007). The analogue method aims at bypassing these local phenomena by using the global circulation information to forecast local precipitation. The basis for such an approach is the presumption that most of the effects of the local processes are already embedded in the precipitation series.

The relevance maps established for the analogue method calibration at two locations in the alpine Rhône catchment show a good coherence with known atmospheric circulation characteristics. More specifically, the most relevant data for the analogue method are located where the atmospheric circulation is dominant during heavy precipitation events (Horton et al., 2010, 2011). As one can see in Fig. 4, the most skilled areas do not include the troughs or lows, but the resulting flow. This is a consequence of the $\mathrm{S} 1$ criteria we use, which is a comparison of the gradient. As far as the authors know, this is the first analysis that sets in perspective the relevance maps and climatology.

The time evolution of the relevance maps confirms that the atmospheric variables have significantly better forecasting skills close to the precipitation period, and that it seems pointless for the analogue method to consider circulation information days before the predictand as a primary predictor. Even though the occurrence of a southerly flow can be detected by precursors at remote locations and one week ahead (Grazzini, 2007; Martius et al., 2008), time extrapolation by the analogue method seems to be rather poor. This may be easily explained by the fact that two similar synoptic situations at a given time are unlikely to evolve analogously over several days, and that other analogous situations will become more relevant. This would suggest that time extrapolation should be done by the GCM and not by the adaptation method. This is consistent with previous studies (Obled et al., 2002; Bontron and Obled, 2005; Marty et al., 2012), as they consider circulation predictors at the day of the precipitation.

Plaut et al. (2001) states that "the presently available operational models provide more accurate forecasts of air mass circulation than of precipitation, especially over mountainous areas". This is also true for specific conditions leading to heavy precipitation events. Grazzini (2007) demonstrated that the GCM of the European Centre for Medium-Range Weather Forecast (ECMWF) performs even better under the specific conditions linked with high precipitation events in the Alpine region than the average conditions. The assertion that synoptic circulations conducive to major events have a superior predictive skill does not imply that precipitation is also more predictable by numerical weather prediction models (Fehlmann and Quadri, 2000; Grazzini, 2007). This is where a statistical approach becomes very interesting: trying to link the well-forecasted atmospheric circulation with local precipitation without the use of complex and error-prone physical processes modelling and parametrizations.

Acknowledgements. The MINERVE project is developed in partnership, by the Swiss Federal Office for Environment (FOEV), Roads and Water courses Service, Energy and Water Power Service of the Wallis Canton and Water, Land and Sanitation Service of the Vaud Canton. The Swiss Weather Services (MeteoSwiss) provides precipitation data and weather forecasts and hydroelectric companies communicate information regarding their hydropower plants. HydroCosmos and Epicard engineering firms contribute to the computer aspects. Scientific developments are entrusted to two entities of the Ecole Polytechnique Federal Lausanne (EPFL), the Hydraulic Constructions Laboratory (LCH) and the Ecohydrology 
Laboratory (ECHO), as well as to the Institute of Geomatics and Analysis of Risk (IGAR) of the University of Lausanne (UNIL). The fruitful collaboration with the Laboratoire d'Étude des Transferts en Hydrologie et Environnement of the Grenoble Institute of Technology (G-INP) was made possible thanks to the Herbette Foundation. NCEP reanalysis data are provided by the NOAA/OAR/ESRL PSD, Boulder, Colorado, USA, from their Web site at http://www.esrl.noaa.gov/psd/.

Edited by: A. Bartzokas

Reviewed by: two anonymous referees

\section{References}

Ben Daoud, A., Sauquet, E., Lang, M., Obled, C., and Bontron, G.: La prévision des précipitations par recherche d'analogues: état de l'art et perspectives, La Houille Blanche, pp. 60-65, doi:10.1051/lhb/2009079, 2009.

Bontron, G. and Obled, C.: L'adaptation probabiliste des prévisions météorologiques pour la prévision hydrologique, La Houille Blanche, pp. 23-28, doi:10.1051/lhb:200501002, 2005.

Brown, T.: Admissible Scoring Systems for Continuous Distributions, Manuscript P-5235, The Rand Corporation, Santa Monica, CA, 22 pp., 1974.

Buzzi, A., Tartaglione, N., and Malguzzi, P.: Numerical simulations of the 1994 Piedmont flood: Role of orography and moist processes, Mon. Weather Rev., 126, 2369-2383, doi:10.1175/15200493(1998)126<2369:NSOTPF>2.0.CO;2, 1998.

Danielsen, E. F.: Trajectories: Isobaric, Isentropic and Actual, J. Atmos. Sci., 18, 479-486, doi:10.1175/15200469(1961)018<0479:TIIAA > 2.0.CO;2, 1961.

Drosdowsky, W. and Zhang, H.: Forecast Verification, chap. Verification of Spatial Fields, pp. 121-136, Wiley, 2003.

Fehlmann, R. and Quadri, C.: Predictability Issues of Heavy Alpine South-Side Precipitation, Meteorol. Atmos. Phys., 72, 223-231, doi:10.1007/s007030050017, 2000.

Fehlmann, R., Quadri, C., and Davies, H. C.: An Alpine Rainstorm: Sensitivity to the Mesoscale Upper-Level Structure, Weather Forecast., 15, 4-28, doi:10.1175/15200434(2000)015<0004:AARSTT>2.0.CO;2, 2000.

García Hernández, J., Horton, P., Tobin, C., and Boillat, J.: MINERVE 2010: Prévision Hydrométéorologique et Gestion de Crues sur le Rhône Alpin, Wasser Energie Luft, 4, 297-302, 2009.

Grazzini, F.: Predictability of a large-scale flow conducive to extreme precipitation over the western Alps, Meteorol. Atmos. Phys., 95, 123-138, doi:10.1007/s00703-006-0205-8, 2007.

Hersbach, H.: Decomposition of the Continuous Ranked Probability Score for Ensemble Prediction Systems, Weather Forecast., 15, 559-570, doi:10.1175/15200434(2000)015<0559:DOTCRP>2.0.CO;2, 2000.

Horton, P., Jaboyedoff, M., and Metzger, R.: Extreme hydrometeorological events in the Swiss Alps linked with air mass trajectories, Geophysical Research Abstracts, EGU General Assembly 2009, held 19-24 April 2009 in Vienna, Austria, 11, 7057, 2009.

Horton, P., Jaboyedoff, M., and Metzger, R.: Identification of the best predictors in the analogs method for severe rainfall in the Swiss Alps, Geophysical Research Abstracts, EGU General As- sembly 2010, held 2-7 May 2010 in Vienna, Austria, 12, 11395, 2010.

Horton, P., Jaboyedoff, M., and Obled, C.: The Analogs method in the framework of severe rainfall forecasting in the Swiss Alps, Geophysical Research Abstracts, EGU General Assembly 2011, held 3-8 April 2011 in Vienna, Austria, 13, 4753, 2011.

Kalnay, E., Kanamitsu, M., Kistler, R., Collins, W., Deaven, D., Gandin, L., Iredell, M., Saha, S., White, G., and Woollen, J.: The NCEP/NCAR 40-Year Reanalysis Project, B. Am. Meteorol. Soc., 77, 437-471, doi:10.1175/15200477(1996)077<0437:TNYRP>2.0.CO;2, 1996.

Lorenz, E.: Atmospheric Predictability as Revealed by Naturally Occuring Analogues, J. Atmos. Sci., 26, 636-646, 1969.

Marsigli, C., Boccanera, F., Montani, A., and Paccagnella, T.: The COSMO-LEPS mesoscale ensemble system: validation of the methodology and verification, Nonlin. Processes Geophys., 12, 527-536, doi:10.5194/npg-12-527-2005, 2005.

Martius, O., Zenklusen, E., Schwierz, C., and Davies, H. C.: Episodes of alpine heavy precipitation with an overlying elongated stratospheric intrusion: a climatology, Int. J. Climatol., 26, 1149-1164, doi:10.1002/joc.1295, 2006.

Martius, O., Schwierz, C., and Davies, H. C.: Far-upstream precursors of heavy precipitation events on the Alpine south-side, Q. J. Roy. Meteorol. Soc., 134, 417-428, doi:10.1002/qj.229, 2008.

Marty, R., Zin, I., Obled, C., Bontron, G., and Djerboua, A.: Towards Real-Time Daily PQPF by an Analog Sorting Approach. Application to Flash Flood Catchments, J. Appl. Meteorol. Climatol., 51, 505-520, doi:10.1175/JAMC-D-11-011.1, 2012.

Massacand, A., Wernli, H., and Davies, H.: Heavy precipitation on the alpine southside: An upper-level precursor, Geophys. Res. Lett., 25, 1435-1438, doi:10.1029/98GL50869, 1998.

Matheson, J. and Winkler, R.: Scoring Rules for Continuous Probability Distributions, Manage. Sci., 22, 1087-1096, doi:10.1287/mnsc.22.10.1087, 1976.

Montani, A., Capaldo, M., Cesari, D., Marsigli, C., Modigliani, U., Nerozzi, F., Paccagnella, T., Patruno, P., and Tibaldi, S.: Operational limited-area ensemble forecasts based on the Lokal Modell, ECMWF Newsletter, 98, 2-7, 2003.

Obled, C., Bontron, G., and Garçon, R.: Quantitative precipitation forecasts: a statistical adaptation of model outputs through an analogues sorting approach, Atmos. Res., 63, 303-324, doi:10.1016/S0169-8095(02)00038-8, 2002.

Petrascheck, A. and Hegg, C.: Hochwasser 2000. Ereignisanalyse/Fallbeispiele. - Les crues 2000. Analyse des événements/Cas exemplaires., Tech. rep., Federal Office for Water and Geology, 2002.

Plaut, G., Schuepbach, E., and Doctor, M.: Heavy precipitation events over a few Alpine sub-regions and the links with largescale circulation, 1971-1995, Clim. Res., 17, 285-302, 2001.

Steppeler, J., Doms, G., Schättler, U., Bitzer, H., Gassmann, A., Damrath, U., and Gregoric, G.: Meso-gamma scale forecasts using the nonhydrostatic model LM, Meteorol. Atmos. Phys., 82, 75-96, doi:10.1007/s00703-001-0592-9, 2003.

Teweles, S. and Wobus, H. B.: Verification of prognostic charts, B. Am. Meteorol. Soc., 35, 455-463, 1954. 